\title{
Mechanism of control of root-feeding nematodes by mycorrhizal fungi in the dune grass Ammophila arenaria
}

\author{
Eduardo de la Peña ${ }^{1}$, Susana Rodríguez Echeverría ${ }^{2}$, Wim H. van der Putten ${ }^{3,4}$, Helena Freitas ${ }^{2}$ and \\ Maurice Moens ${ }^{1,5}$ \\ ${ }^{1}$ CLO, Agricultural Research Centre, Burg. Van Gansberghelaan 96, B-9820, Merelbeke, Belgium; ${ }^{2}$ IMAR, Departamento de Botânica, Universidade de \\ Coimbra, PT-3000 Coimbra, Portugal; ${ }^{3}$ Netherlands Institute of Ecology (NIOO-KNAW), Department of Multitrophic Interactions, PO Box 40 , NL-6666 \\ ZG Heteren, the Netherlands; ${ }^{4}$ Laboratory of Nematology, Wageningen University and Research Centre, PO Box 8123, NL-6700 ES Wageningen, the \\ Netherlands; ${ }^{5}$ Laboratory of Agrozoology, Gent University, Coupure 653, B-9000 Gent, Belgium
}

Author for correspondence: Eduardo de la Peña

Tel: +3292722446

Fax: +3292722429

Email: e.delapena@clo.fgov.be

Received: 7 July 2005

Accepted: 26 September 2005

\section{Summary}

- Root-feeding herbivores can affect plant performance and the composition of natural plant communities, but there is little information about the mechanisms that control root herbivores in natural systems. This study explores the interactions between the pioneer dune grass Ammophila arenaria, arbuscular mycorrhizal fungi (AMF) and the root-feeding nematode Pratylenchus penetrans.

- Our objectives were to determine whether AMF can suppress nematode infection and reproduction and to explore the mechanisms of nematode control by AMF. A sequential inoculation experiment and a split-root experiment were designed to analyse the importance of plant tolerance and resistance and of direct competition between $\mathrm{AMF}$ and $P$. penetrans for the root herbivore and the plant.

- Root infection and multiplication of $P$. penetrans were significantly reduced by the native inoculum of AMF. Plant preinoculation with AMF further decreased nematode colonization and reproduction. Nematode suppression by AMF did not occur through a systemic plant response but through local mechanisms.

- Our results suggest that AMF are crucial for the control of root-feeding nematodes in natural systems and illustrate that locally operating mechanisms are involved in this process.

Key words: bottom-up control, coastal dunes, multitrophic interactions, nematode control, plant mutualists, Pratylenchus sp., root-feeding nematodes.

New Phytologist (2006) 169: 829-840

(c) The Authors (2005). Journal compilation (C) New Phytologist (2005)

doi: $10.1111 / \mathrm{j} .1469-8137.2005 .01602 . x$

\section{Introduction}

Below-ground plant pathogens, parasites, herbivores and mutualists influence the performance and competitive ability of plant species and their offspring (Klironomos, 2002; Reinhart et al., 2003; De Deyn et al., 2004). Plants also selectively affect the soil biota associated with their rhizosphere (Wardle, 2002) and, as a consequence, feedback interactions are established between plants and soil organisms. These interactions are crucial for the spatial and temporal composition of natural plant communities (Gange \& Brown, 2002; Bever, 2003). The sign of these feedbacks (positive or negative) can also change depending on the multitrophic interactions between different rhizosphere organisms (van der Putten, 2003). However, below-ground interactions that include more than one group of soil organisms have been largely ignored in ecological studies.

In coastal sand dunes, soil-borne pathogenic fungi and root-feeding nematodes are responsible for the degeneration of Ammophila arenaria, which in turn leads to plant succession (van der Putten et al., 1988, 1993). Coastal foredunes are highly dynamic ecosystems characterized by severe wind-driven sand accretion. Not only is A. arenaria resistant to sand burial, but it needs sand accretion in order to maintain vigorous growth. Sand burial allows $A$. arenaria to avoid ageing by 
developing new roots (Marshall, 1965) and provides the opportunity to escape temporarily from root-pathogens and herbivores (van der Putten et al., 1990). Although root-feeding nematodes gradually colonize the new sand layers, there is a lag of 4-5 wk in which the new roots grown in a freshly deposited layer of wind-blown beach sand are in an 'enemyfree' environment (de Rooij-van der Goes et al., 1998; van der Stoel et al., 2002). When sand accretion stops, as in stabilized dunes, root pathogens and herbivores accumulate in the rhizosphere leading to a gradual degeneration and eventual disappearance of $A$. arenaria.

Among the root-feeding nematodes that accumulate in the rhizosphere of $A$. arenaria, the endoparasitic genus Pratylenchus (root lesion nematode) is of special relevance. This genus has a wide distribution along the Atlantic and Mediterranean coasts in Europe (Karssen et al., 2001), and occurs at relatively high densities in later stages of dune succession (Zoon et al., 1993). Pratylenchus are migratory endoparasitic nematodes that invade, multiply, feed and move on the root cortex of the host plant resulting in necrotic lesions and promoting fungal infections (Back et al., 2002). Moreover, Pratylenchus penetrans, which is considered a serious pest on a wide range of economically important crops (Pinochet $e t$ al., 1996), is also supposed to be a key factor in the die-out of the North-American Ammophila breviligulata (Seliskar \& Huettel, 1993).

The deleterious effect of root-feeding nematodes on plant growth is dependent on the combination of nematode species (Brinkman et al., 2005), as well as on the density of nematodes in the rhizosphere. However, in dune soils the density of rootfeeding nematodes is considerably lower than that observed when nematodes are added to plants growing in sterilized soil (de Rooij-van der Goes, 1995; Brinkman et al., 2004). Such nematode control in natural systems may be explained by bottom-up mechanisms (by the host-plant), top-down control (by natural enemies) and control by plant mutualists (e.g. arbuscular mycorrhizal fungi and endophytes).

The role of arbuscular mycorrhizal fungi (AMF) as protective agents against root-feeding nematodes has been tested in crop plant species with highly variable results (Hol \& Cook, 2005). One major limitation of those studies is the use of commercial strains of AMF which had not coevolved with the crop and the nematodes. The diversity of AMF found in natural communities might be important for the outcome of the interaction because of the functional differences between different AMF taxa (Klironomos, 2003). In coastal sand dunes, AMF account for $30 \%$ of the total soil microbial biomass (Olsson \& Wilhelmsson, 2000). It is therefore reasonable to assume that they play an important role in these systems. Based on studies with A. breviligulata and Leymus arenarius, arbuscular mycorrhizal fungi are considered to be a major candidate for nematode control in foredunes (Little \& Maun, 1996; Greipsson \& El-Mayas, 2002), but no data are available for most other sand dune plant species or for the putative mechanisms involved in nematode control.
Plant protection by AMF might be caused by physical and physiological plant responses to the fungal infection (Graham, 2001). Alternatively, AMF could have a direct suppressive effect on root-feeding nematodes if both organisms compete for root space and feeding sites (Francl, 1993). We used A. arenaria because it is one of the very few wild plant species for which there is a wide knowledge about interactions with root-feeding nematodes. Two experiments were designed to study the mechanisms by which AMF may control rootfeeding nematodes, using $A$. arenaria and $P$. penetrans as model organisms. In the first experiment we examined whether preinoculation with AMF makes plants more tolerant to herbivory or provides an increase in plant resistance to the herbivores. In the second experiment, we analysed the importance of the presence of arbuscular mycorrhizal fungi and $P$. penetrans in the same root compartment of $A$. arenaria for the outcome of the interaction. The results obtained from both experiments provide new clues to understand the mechanisms of control of root-feeding nematodes by AMF in natural systems.

\section{Materials and Methods}

\section{Plants and soil}

In August 2003, seeds of $A$. arenaria (L.) Link were collected from plants in the nature reserves of Het Zwin, KnokkeHeist, Belgium $\left(51^{\circ} 21^{\prime} \mathrm{N}, 03^{\circ} 22^{\prime} \mathrm{E}\right)$ and Ynyslas, Wales, UK $\left(52^{\circ} 31^{\prime} \mathrm{N}, 04^{\circ} 03^{\prime} \mathrm{W}\right)$. Seeds were germinated in a glasshouse with a $16 \mathrm{~h} / 8 \mathrm{~h}$ light/dark regime and $25^{\circ} \mathrm{C} / 16^{\circ} \mathrm{C}$ day/night temperature on 2-mm diameter glass beads with demineralized water. Two-week-old seedlings with 2 -cm tall shoots were used in the bioassays. Seedlings of Belgian and Welsh origin were used for experiments 1 and 2, respectively.

Sand was collected from a monospecific stand of $A$. arenaria on the seaward slope of foredunes in Het Zwin, Knokke-Heist, Belgium. The sand was taken from the upper $30 \mathrm{~cm}$ dune layer and stored in plastic bags at $4^{\circ} \mathrm{C}$ until use. Before being used the sand was sieved with a $2-\mathrm{mm}$ sieve to remove pebbles and roots and sterilized by autoclaving at $120^{\circ} \mathrm{C}, 1 \mathrm{~atm}$ for $2 \mathrm{~h}$.

\section{Nematodes}

Pratylenchus penetrans was collected from Zandhoven (Belgium) and multiplied in $A$. arenaria growing in autoclaved sand in 15-1 PVC pots for 8 months before experimental set-up. Pots were watered biweekly and once a month they were fertilized with half-strength Hoagland's solution. To extract nematodes for inoculation experiments, soil and plant roots were sieved through a $0.5-\mathrm{cm}$ mesh and the roots were chopped into $1-\mathrm{cm}$ fragments and placed in a funnel over a cotton filter. The funnels were placed in a mist chamber at $20^{\circ} \mathrm{C}$, and tapped off every day for $1 \mathrm{wk}$ to collect nematodes in a water suspension. In both experiments, we added 900 nematodes (mobile stages) per pot. 


\section{Arbuscular mycorrhizal fungi}

In November 2003, soil was collected from the rhizosphere of four different $A$. arenaria plants in Het Zwin (Belgium) and Ynyslas (Wales) and used to set up trap cultures of the AMF community with Zea mays L. as host plant. The trap cultures were maintained in a plant growth chamber with a $16 \mathrm{~h} / 8 \mathrm{~h}$ light/dark regime at $24^{\circ} \mathrm{C} / 16^{\circ} \mathrm{C}$ and watered regularly. After 5 months, plants were harvested and roots examined to confirm AMF colonization. A portion of the roots was stained with ink (Blue Quink; Parker, Jansville, WI, USA) following a modification of the protocol of Vierheilig et al. (1998); roots were cleared in $2.5 \%(\mathrm{w}: \mathrm{v}) \mathrm{KOH}$ for $1 \mathrm{~h}$ at $90^{\circ} \mathrm{C}$, rinsed with tap water and immersed in $1 \% \mathrm{HCl}$ overnight, and stained with $1 \%(\mathrm{v}: \mathrm{v})$ ink in $1 \% \mathrm{HCl}$ for $30 \mathrm{~min}$ at $60^{\circ} \mathrm{C}$. Root colonization was estimated under a stereoscopic microscope (Leica MZ 8) using the gridline intersect method (Giovannetti $\&$ Mosse, 1980). After verifying root colonization, the remaining corn roots were cut into 2 -cm pieces, and disinfected by immersion in 2\% chloramine $\mathrm{T}$ for $3 \mathrm{~min}$ and in an antibiotic solution (streptomycin $200 \mathrm{mg} \mathrm{l}^{-1}+$ penicillin $100 \mathrm{mg} \mathrm{l}^{-1}$ ) for $3 \mathrm{~h}$. The roots were then rinsed with autoclaved water and air dried (Little \& Maun, 1996).

Spores were extracted from the trap cultures by wet sieving. The material retained in the $0.250-\mathrm{mm}, 0.100-\mathrm{mm}$ and $0.045-\mathrm{mm}$ sieves was collected and assessed under a stereoscopic microscope (Leica MZ 8). Spores of Scutellospora castanea and several Glomus spp. were observed in the trap cultures from Belgium, while in the trap cultures from Wales the spores were mainly from Glomus spp. Healthy spores of both cultures were collected, washed and resuspended in autoclaved distilled water to a final concentration of 100 spores $\mathrm{ml}^{-1}$.

For the first experiment, 550 spores and $0.5 \mathrm{~g}$ of dried corn roots from the Belgian trap cultures were used to inoculate each pot containing four $A$. arenaria seedlings. For the splitroot experiment, 50 spores and $0.3 \mathrm{~g}$ of corn roots from the trap cultures of Wales were used to inoculate each plant. Corn roots were mixed with the autoclaved sand and spores were inoculated by adding the appropriate volume of spore suspension to the rhizosphere of each $A$. arenaria seedling.

\section{Experiment 1: sequential inoculation}

Four seedlings of $A$. arenaria were planted in 1.5-1 pots filled with $1800 \mathrm{~g}$ of sterilized dune sand. Pots were covered with aluminium foil to prevent desiccation and watered every second day to keep the moisture content at $5-10 \%$ based on pot weight. Every $2 \mathrm{wk}$ all treatments received $120 \mathrm{ml}$ halfstrength modified (P-free) Hoagland's nutrient solution. There were six treatments with six replicates per treatment: an uninoculated control (C), inoculation with arbuscular mycorrhizal fungi (AMF), inoculation with P. penetrans (Nem), simultaneous inoculation with AMF and nematodes (FN), inoculation with AMF and 2 wk later with nematodes (FN2), and inoculation with AMF and 5 wk later with nematodes (FN5). In addition, we included four pots inoculated with AMF for infection assessment after $2 \mathrm{wk}$ and $5 \mathrm{wk}$. Root colonization was only detected in plants harvested after $5 \mathrm{wk}$. The pots were placed in the glasshouse in a randomized design and repositioned every $2 \mathrm{wk}$, after each fertilizer application. The experiment was conducted from June 2004 until September 2004.

\section{Experiment 2: split root experiment}

Two-week-old seedlings were transferred to 1.5-1 pots with sterilized soil and grown for six additional weeks to obtain roots big enough to be split. Afterwards, the roots of each plant were split in half and each fraction was placed into a separate pot with $800 \mathrm{ml}$ of sterilized dune sand. Pots were covered with aluminium foil to avoid desiccation and prevent contamination and placed in a growth chamber randomly. Growth conditions were $16 \mathrm{~h} / 8 \mathrm{~h}$ day $/$ night at $24^{\circ} \mathrm{C} / 18^{\circ} \mathrm{C}$ and $80 \%$ humidity. Pots were watered weekly to maintain $5-10 \%$ moisture and were fertilized every 2 wk with $100 \mathrm{ml}$ of half-strength modified (P-free) Hoagland's solution. Arbuscular mycorrhizal fungi and nematodes were inoculated either together or alone in each root subsystem when plants were transferred to the split root systems. The experiment included five treatments with nine replicates per treatment: uninoculated plants $(\mathrm{C})$; inoculation with nematodes (Nem); inoculation with AMF (AMF); AMF and nematodes inoculated separately (Split), and nematodes and AMF inoculated together in each root subsystem (FN).

\section{Harvest and data collection}

Plants from both experiments were harvested after $14 \mathrm{wk}$. The fresh weight of shoots and roots, the number of tillers and leaves, and the length of the longest leaf were measured for each plant. A portion of each root was weighed and stained using acid fuchsin for nematode and AMF assessment (Baker \& Gowen, 1996). Using a compound microscope, root infection by AMF and nematodes was estimated as the percentage of $1-\mathrm{cm}$ root fragments containing structures of each or both organisms (Fig. 1). Nematodes were also counted in each root fragment and the mean number of nematodes present in each infected $1-\mathrm{cm}$ root fragment was calculated. The total number of nematodes per gram of root was estimated using the weight of the root portion used in the staining process.

Nematodes were extracted from soil by zonal centrifugation following Hendrickx (1995); $100 \mathrm{ml}$ of sand from each pot were stirred in $1000 \mathrm{ml}$ of water and half of the suspension was centrifuged for nematode extraction. Nematodes were counted in $120 \mathrm{ml}$ of the eluted suspension. Nematodes in any developmental stage were taken as a positive count. Because in experiment 1 the nematodes were added at different 


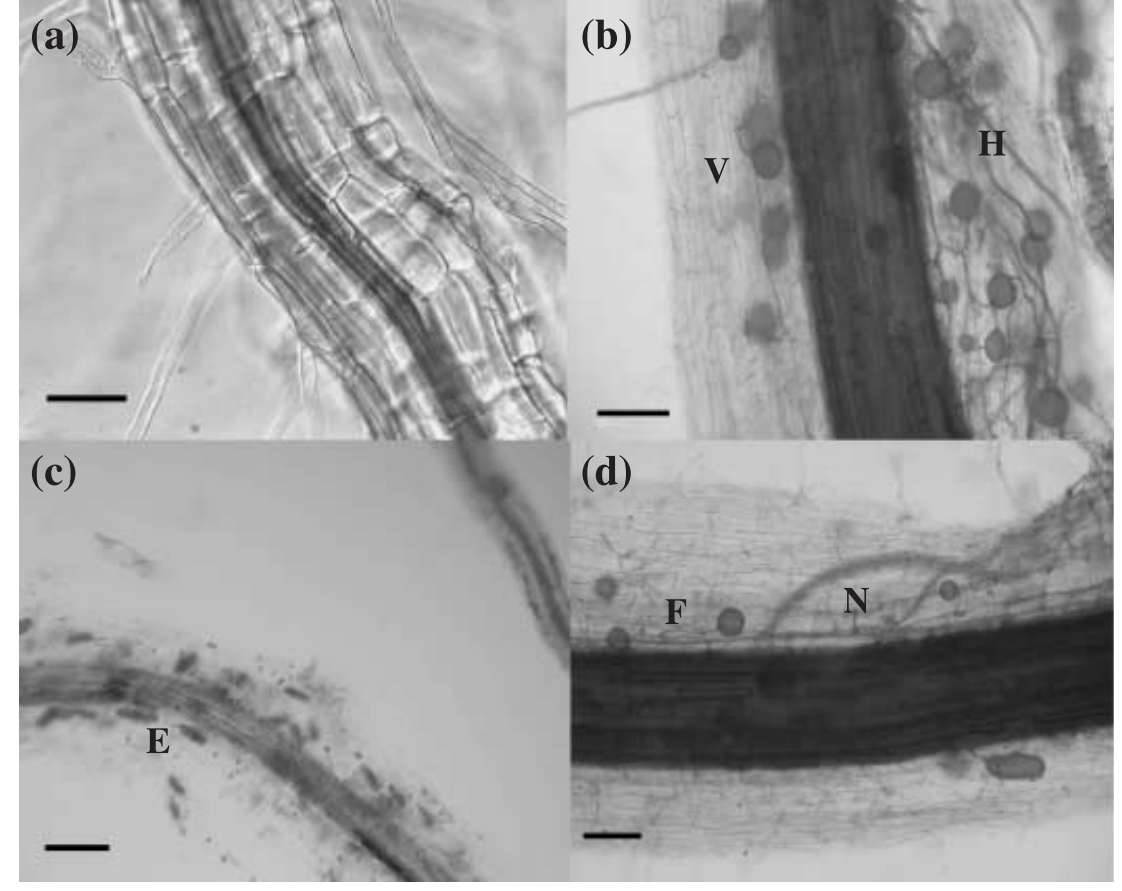

Fig. 1 Ammophila arenaria roots stained with acid fuchsin to detect infection by arbuscular mycorrhizal fungi (AMF) and nematodes. (a) Uninfected root; (b) AMF colonization ( $\mathrm{V}$, vesicles; $\mathrm{H}$, hyphae); (c) Necrotic root infested with nematode eggs (E); (d) Root infected with AMF (F) and adult nematodes $(\mathrm{N})$. Bar, $100 \mu \mathrm{m}$. times, we calculated the rate of nematode multiplication rate per day $\left(\mathrm{Nr} \mathrm{t}^{-1}\right)$ by computing the ratio between the total number of nematodes (in roots and soil) at the end of the experiment and the initial number of nematodes added to each pot, and dividing this value by the number of days that the roots were exposed to nematodes ( $98 \mathrm{~d}$ for Nem and FN, $84 \mathrm{~d}$ for FN2 and $63 \mathrm{~d}$ for FN5). After taking the root fraction for assessing colonization, the remaining plant material was dried at $72^{\circ} \mathrm{C}$ for $48 \mathrm{~h}$ to estimate plant biomass. Subsequently, leaves and roots were separated manually and ground using an electric mill (Culatti MFC, Zürich, Switzerland). Plant carbon $(\mathrm{C})$ and nitrogen $(\mathrm{N})$ contents were measured by combustion using an automatic elemental analyser FlashEA 1112 coupled with gas chromatographic (GC) separation and thermal conductivity detection (TCD) systems (ThermoFinnigan, CA, USA). Phosphorus analyses could not be performed because of lack of plant material.

\section{Analysis of AMF diversity}

Total DNA was extracted from the roots of plants inoculated with AMF in both experiments. In experiment 1, DNA was extracted from all replicates of the treatment AMF and whereas in experiment 2, DNA extraction was done from the plants in the three treatments that included AMF inoculation. DNA was extracted from $1-\mathrm{cm}$ root fragments by crushing them in sterile 1.5 -ml tubes using a micropestle in $60 \mu$ of TE buffer $\mathrm{pH} 8.0(10 \mathrm{mM})$, adding $40 \mu \mathrm{l}$ of $20 \%$ Chelex 100 (BioRad, Hemel Hempstead, UK) and incubating the extract at $95^{\circ} \mathrm{C}$ for $10 \mathrm{~min}$. After cooling on ice for $15 \mathrm{~min}$ the extract was centrifuged at $12000 \mathrm{~g}$ for $4 \mathrm{~min}$ and the supernatant transferred to a sterile tube (van Tuinen et al., 1998).

A nested-polymerase chain reaction (PCR) was used to selectively amplify fungal DNA from the extracts. All reactions were carried out in a GeneAmp PCR 9700 system (Perkin Elmer, CA, USA). The first PCR used the forward primer NS1 in combination with the reverse primer ITS4, covering the region from the beginning of the $18 \mathrm{~S}$ rRNA gene through the $5^{\prime}$ end of the 25S rRNA gene (White et al., 1990). The PCRs were performed in a final volume of $20 \mu \mathrm{l}$ using $1 \mu \mathrm{l}$ of a $1: 10$ dilution of the DNA extract, $200 \mu \mathrm{M}$ of each dNTP (Amersham-Pharmacia Biotech Europe, $\mathrm{GmbH}$, Barcelona, Spain), $1.5 \mathrm{~mm} \mathrm{MgCl}_{2}$, $0.4 \mu \mathrm{M}$ of each primer, and $1 \mathrm{U}$ of the Taq DNA polymerase (Amersham-Pharmacia). The conditions for the PCR were $94^{\circ} \mathrm{C}$ for $4 \mathrm{~min}, 30$ cycles of $94^{\circ} \mathrm{C}$ for $30 \mathrm{~s}, 55^{\circ} \mathrm{C}$ for $40 \mathrm{~s}$ and $68^{\circ} \mathrm{C}$ for $2 \mathrm{~min}+5 \mathrm{~s}$ per cycle, and $68^{\circ} \mathrm{C}$ for $7 \mathrm{~min}$. The product of this first PCR was diluted and used in the second PCR with the primers NS31 (Simon et al., 1992) and AM1 (Helgason et al., 1998) targeted at the region V3-V4 of the $18 \mathrm{~S}$ rRNA gene and designed to specifically amplify AMF sequences. Thermocycling used the following program: $94^{\circ} \mathrm{C}$ for $2 \mathrm{~min}, 35$ cycles of $92^{\circ} \mathrm{C}$ for $30 \mathrm{~s}, 61^{\circ} \mathrm{C}$ for $60 \mathrm{~s}$ and $68^{\circ} \mathrm{C}$ for $50 \mathrm{~s}+1 \mathrm{~s}$ per cycle), and $68^{\circ} \mathrm{C}$ for $5 \mathrm{~min}$. The products from the second PCR were examined by standard $1 \%(\mathrm{w}: \mathrm{v})$ agarose gel electrophoresis with ethidium bromide staining, to confirm product integrity and estimate yield. Afterwards, they were purified using the QiaQuick PCR purification kit (Qiagen, Courtaboeuf, France) with a final elution volume of $30 \mu \mathrm{l}$. Cloning of the purified products was done using the pGEM-T Easy Vector System from Promega (Madison, WI, USA) according to the manufacturer's 
New

Phytologist

protocol. Three colonies from each cloning reaction were grown overnight at $37^{\circ} \mathrm{C}$ with shaking at 200 r.p.m. in $3 \mathrm{ml}$ of Luria-Bertani medium supplemented with $100 \mathrm{mg} \mathrm{ml}^{-1}$ ampicillin and plasmids were purified using the Qiagen Kit following the manufacturer's protocol. Positive clones were sequenced using ABI PRISM Dye Terminator Cycle Sequence Ready Reaction Kit (Perkin-Elmer, Norwalk, CA, USA).

All sequences were compared with sequences in internet databases using BLAST to check for similarities with previously described species (Altschul et al., 1997). Sequences of Glomus sp. and two outgroup taxa (Endogone pisiformis Link (X58724), Mortierella polycephala Coem. (X89436) were acquired from GenBank/EMBL databases and used in the phylogenetic analyses. Sequences were aligned using BIOEDIT (Hall, 1999) and neighbour-joining analyses were performed with Kimura parameters (Kimura, 1980) using PHYLYP 3.5 (Felsenstein, 1993). The input order of species was randomized and analyses were bootstrapped. Trees were visualized with TREEVIEW 1.6.6 (Page, 2001).

\section{Statistical analysis}

The statistical analysis was performed with the ANOVA General Linear Model (SPSS for Windows, Rel. 11.0.1; SPSS Inc., Chicago, IL, USA). All data were checked for normality with Kolmogorov-Smirnov and homogeneity of variance with Levene's test and $\log X, \log (X+1)$ or square-root transformed when needed to meet ANOVA model assumptions. Data on biomass, nutrient content, AMF colonization and nematode infection and multiplication were analysed with one-way ANOVA and Tukey's multiple range test for overall comparisons. When ANOVA assumptions were not achieved (tiller, longest leaf length and leaf number) a nonparametric Kruskal-Wallis test and pairwise comparisons using Mann-Whitney test were performed to detect differences among treatments.

\section{Results}

\section{Experiment 1: sequential inoculation}

Root infection by AMF ranged from $43 \%$ (FN) to $55 \%$ (AMF) (Fig. 2a). However, no significant differences for root infection by AMF were found between treatments. Root colonization by nematodes ranged between $2 \%$ and $29 \%$, again depending on the treatment (Fig. 2b). Nematode infection was lower when AMF were also present in the root, and significant differences were found $\left(F_{3,18}=21.21, P<0.005\right)$ between the treatments previously inoculated with AMF (i.e. FN2 and FN5) and the other two treatments (i.e. Nem and FN). The total number of nematodes per pot was also drastically reduced by the presence of AMF (Fig. 2c), from 2863 (Nem) to 1516 (FN). A further reduction to less than 1000 in FN2 and FN5 was, at in part, due to shorter reproduction time of the nematodes that were inoculated $2 \mathrm{wk}$ and $5 \mathrm{wk}$ later. Significant differences $\left(F_{3,18}=37.71, P<0.001\right)$ were found between all treatments except when comparing FN2 and FN5.

To avoid misinterpretation owing to differences in inoculation times between FN, FN2 and FN5 in the sequential experiment, we calculated nematode multiplication per day and the number of nematodes per unit of infection, i.e. $1-\mathrm{cm}$ root pieces (Fig. 3). The ratio of nematode multiplication per day $\left(\mathrm{Nr} \mathrm{t}^{-1}\right)$ decreased with the presence of AMF (Fig. 3a). Significant differences $\left(F_{3,18}=28.81 ; P<0.001\right)$ were found between the plants inoculated only with nematodes and those inoculated with both AMF and nematodes. Nematode multiplication was significantly lower in the treatment FN5 when compared with FN, showing that the lower number of nematodes did not result purely from shorter multiplication time. The average number of nematodes per infected root was more than two times higher in Nem than in each of the other treatments (Fig. 3b). This value was significantly different $\left(F_{3,18}=\right.$
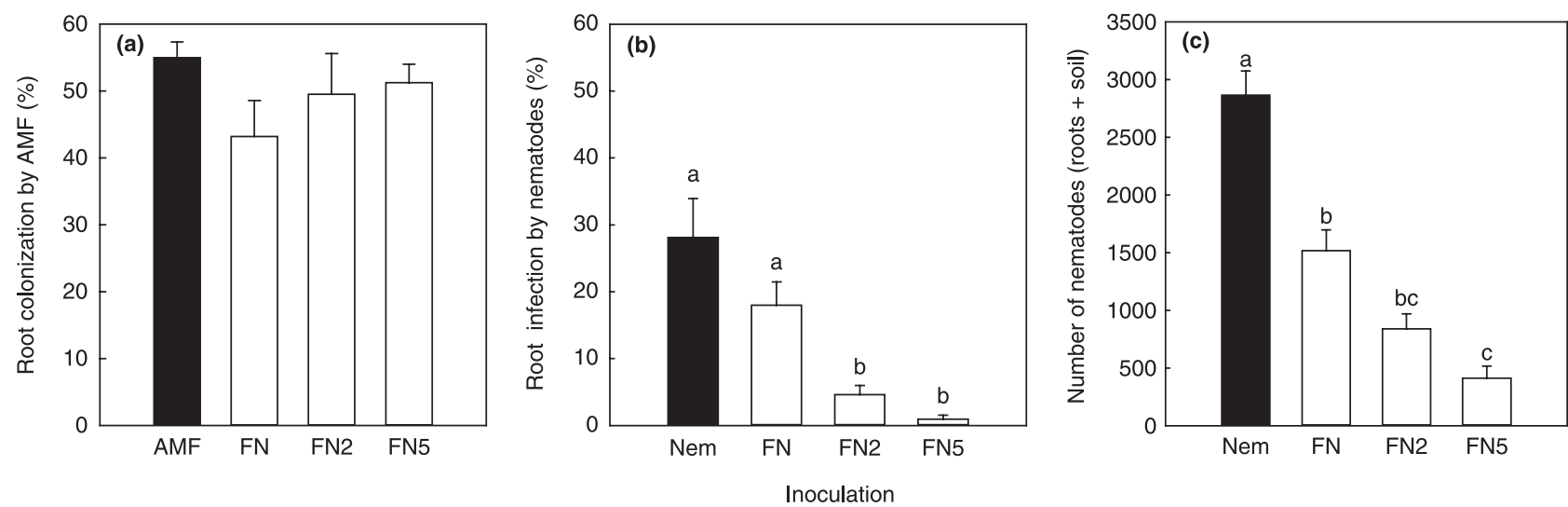

Fig. 2 Sequential inoculation experiment. (a) Percentage of Ammophila arenaria roots infected by arbuscular mycorrhizal fungi (AMF), (b) percentage of $A$. arenaria roots infected by Pratylenchus penetrans and (c) total final number of nematodes. Data are mean $\pm S E$. AMF, inoculation with AMF; Nem, inoculation with nematodes; FN, inoculation with AMF and nematodes; FN2, nematode inoculation 2 wk after AMF; FN5, nematode inoculation 5 wk after AMF. Different letters above the bars indicate significant differences $(P<0.005)$ between treatments after one-way ANOVA and Tukey's HSD test. 

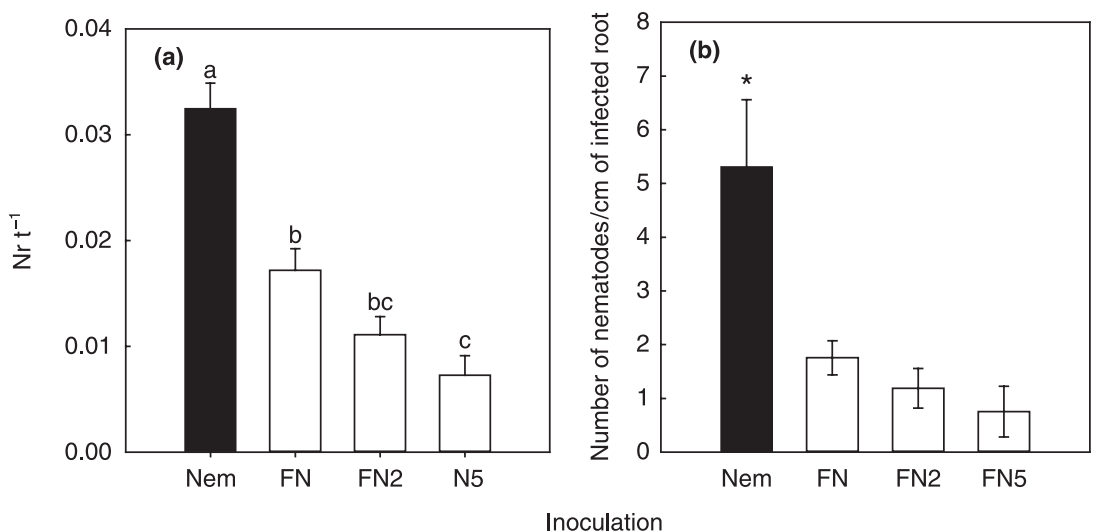

Fig. 3 Sequential inoculation experiment. (a) Ratio of nematode multiplication per day $\left(\mathrm{Nr} \mathrm{t}^{-1}\right)$ ((final number of nematodes/initial number of nematodes)/days) and (b) number of nematodes per fragment of root infected. Data are mean $\pm \mathrm{SE}$. Nem, inoculation with nematodes; $\mathrm{FN}$, inoculation with arbuscular mycorrhizal fungi (AMF) and nematodes; FN2, nematode inoculation $2 \mathrm{wk}$ after AMF; FN5, nematode inoculation $5 \mathrm{wk}$ after AMF. Different letters above the bars indicate significant differences $(P<0.001)$ between treatments after one-way ANOVA and Tukey's HSD test.
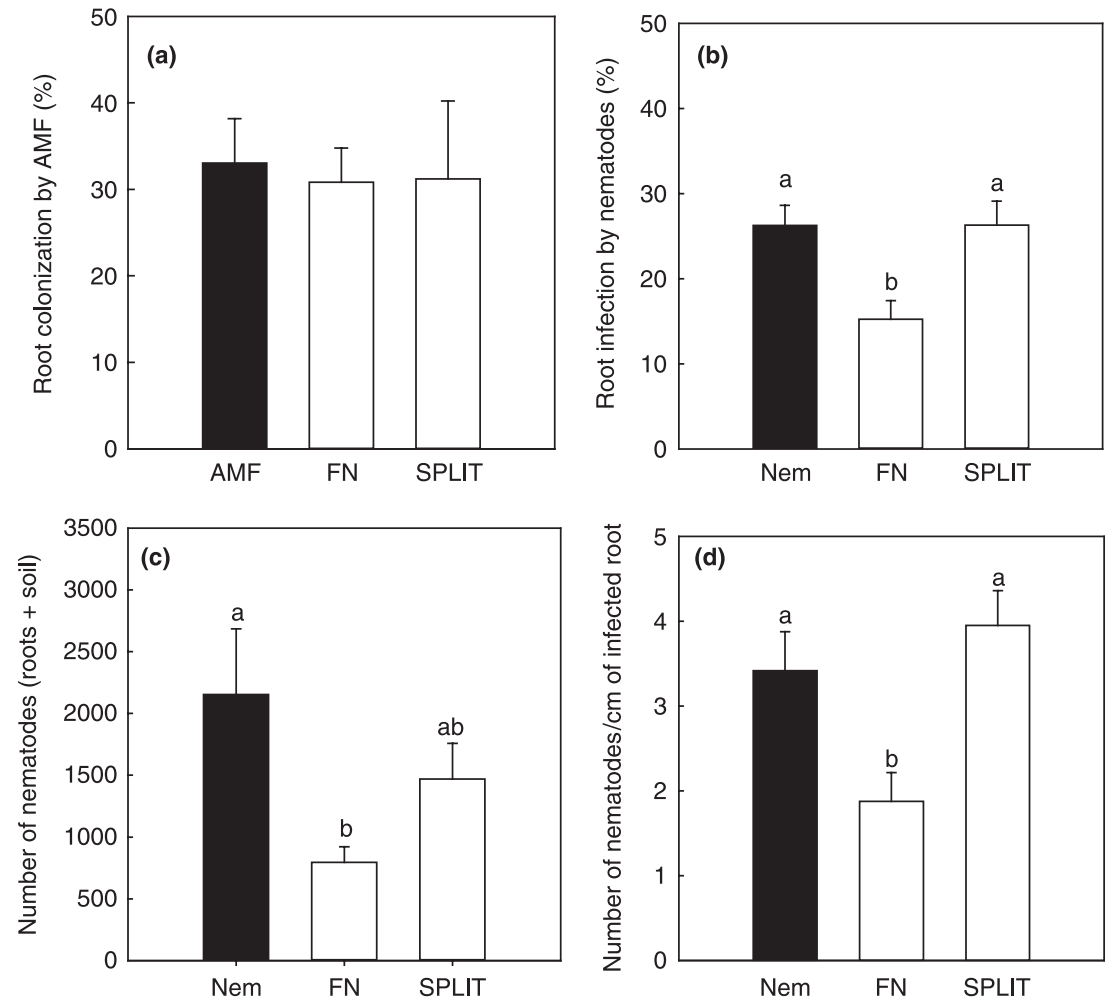

Fig. 4 Split-root experiment. (a) Percentage of Ammophila arenaria roots infected by arbuscular mycorrhizal fungi (AMF), (b) percentage of $A$. arenaria roots infected by Pratylenchus penetrans, (c) total number of nematodes and (d) number of nematodes per fragment of root infected. Data are mean $\pm \mathrm{SE}$. AMF, inoculation with $\mathrm{AMF} ; \mathrm{Nem}$, inoculation with nematodes; $F N$, inoculation with AMF and nematodes; SPLIT, split inoculation of AMF and nematodes. Different letters above the bars indicate significant differences $(P<0.05)$ between treatments after one-way ANOVA and Tukey's HSD test.

7.78; $P<0.005)$ from the treatments that included AMF. No significant differences were found between FN, FN2 and FN5.

Plant biomass was significantly higher $\left(F_{5,124}=5.02 ; P<\right.$ $0.001)$ in the AMF than in control, Nem and FN treatments (Table 1). At the nematode density used in the experiment, no negative effect on plant biomass was observed, but the inoculation with nematodes at the same time as AMF and $2 \mathrm{wk}$ after AMF inoculation suppressed the beneficial effect of mycorrhizal fungi on plant biomass. The proportion of biomass allocated below-ground (root : total biomass ratio) was significantly higher in the AMF and FN treatments than in control plants $\left(F_{5,124}=6.68 ; P<0.001\right)$ (Table 1$)$. Colonization by AMF significantly increased the number of leaves and tillers produced by $A$. arenaria plants, whereas nematode infection significantly reduced the number of tillers (Table 1 ).
Inoculation with AMF and nematodes affected plant nutrient content and allocation (Table 2). The plants inoculated only with nematodes had the lowest $\mathrm{N}$ content, which was significantly different $\left(F_{5,25}=13.94 ; P<0.001\right)$ from the other values. The same was observed for the proportion of $\mathrm{N}$ allocated below ground and for total $C$ content $\left(F_{5,25}=16.75\right.$, $\left.F_{5,25}=7.41 ; P<0.001\right)$, although no differences were found in total $\mathrm{C}$ between Nem and FN. The proportion of $\mathrm{C}$ allocated below ground was significantly higher in the treatment Nem than in the control $\left(F_{5,25}=6.56 ; P<0.001\right)$ (Table 2).

\section{Experiment 2: split root experiment}

Root colonization by AMF was lower in this experiment with values c. 30\% (Fig. 4a). No significant differences in the 
Table 1 Ammophila arenaria total biomass, root : total biomass ratio, length of longest leaf, number of tillers and number of leaves in experiment 1

\begin{tabular}{|c|c|c|c|c|c|c|c|c|c|}
\hline \multirow[b]{2}{*}{ Variable } & \multicolumn{9}{|l|}{ Treatments } \\
\hline & C & Nem & AMF & $\mathrm{FN}$ & FN2 & FN5 & $F$ & $\mathrm{df}$ & $\chi^{2}$ \\
\hline Biomass (d. wt) (g) & $0.35 \pm 0.03^{a}$ & $0.36 \pm 0.02^{\mathrm{a}}$ & $0.56 \pm 0.04^{b}$ & $0.37 \pm 0.03^{a}$ & $0.40 \pm 0.02^{\mathrm{ab}}$ & $0.49 \pm 0.05^{\mathrm{ab}}$ & $5.02 * * *+$ & 5 & - \\
\hline Root : total & $0.18 \pm 0.01^{\mathrm{a}}$ & $0.22 \pm 0.01^{a b c}$ & $0.26 \pm 0.01^{c}$ & $0.24 \pm 0.01^{b c}$ & $0.20 \pm 0.01^{\mathrm{ab}}$ & $0.18 \pm 0.02^{\mathrm{a}}$ & $6.68 * * *$ & 5 & - \\
\hline Longest leaf $(\mathrm{cm})$ & $60.32 \pm 2.37$ & $62.57 \pm 2.23$ & $66.46 \pm 1.83$ & $62.19 \pm 1.76$ & $66.71 \pm 1.80$ & $65.74 \pm 2.23$ & - & 5 & 9.96 nsł \\
\hline Tillers & $1.64 \pm 0.12^{c d}$ & $1.17 \pm 0.08^{a}$ & $2.38 \pm 0.15^{b}$ & $1.52 \pm 0.12^{c}$ & $1.90 \pm 0.14^{d}$ & $2.07 \pm 0.16^{b c d}$ & - & 5 & $42.96 * * *$ \\
\hline Leaves & $3.95 \pm 0.17^{\mathrm{a}}$ & $3.57 \pm 0.12^{\mathrm{a}}$ & $4.96 \pm 0.20^{b}$ & $4.04 \pm 0.17^{a}$ & $4.85 \pm 0.29^{b}$ & $3.93 \pm 0.16^{\mathrm{a}}$ & - & 5 & $37.44 * * * \neq$ \\
\hline
\end{tabular}

Data are mean \pm SE. C, Control; Nem, inoculation with nematodes; AMF, inoculation with arbuscular mycorrhizal fungi and nematodes; FN, inoculation with arbuscular mycorrhizal fungi and nematodes; FN2, nematode inoculation $2 \mathrm{wk}$ after AMF; FN5 nematode inoculation 5 wk after AMF. Different letters indicate significant differences between treatments according to one-way ANOVA and Tukey's HSD test ( $\dagger$ ) or nonparametric tests $(\ddagger) .{ }^{* *}, P<0.001 ;$ ns, nonsignificant.

Table 2 Ammophila arenaria plant nitrogen and carbon content and percentage of nitrogen and carbon allocated below-ground in experiment 1

\begin{tabular}{|c|c|c|c|c|c|c|c|c|}
\hline \multirow[b]{2}{*}{ Variable } & \multicolumn{8}{|l|}{ Treatments } \\
\hline & $\mathrm{C}$ & $\mathrm{Nem}$ & AMF & $\mathrm{FN}$ & FN2 & FN5 & $\mathrm{df}$ & $F$ \\
\hline Plant nitrogen $(\% \mathrm{w}: \mathrm{w})$ & $1.29 \pm 0.04^{\mathrm{a}}$ & $0.75 \pm 0.09^{b}$ & $1.43 \pm 0.13^{\mathrm{a}}$ & $1.51 \pm 0.04^{\mathrm{a}}$ & $1.49 \pm 0.05^{\mathrm{a}}$ & $1.47 \pm 0.09^{\mathrm{a}}$ & 5 & $13.94 * * *$ \\
\hline Percentage of below-ground nitrogen & $35.11 \pm 0.86^{a}$ & $23.39 \pm 2.75^{b}$ & $40.44 \pm 1.80^{\mathrm{a}}$ & $34.92 \pm 1.20^{\mathrm{a}}$ & $40.79 \pm 1.01^{\mathrm{a}}$ & $41.00 \pm 1.62^{\mathrm{a}}$ & 5 & $16.75^{* * *}$ \\
\hline Plant carbon $(\% \mathrm{w}: \mathrm{w})$ & $39.32 \pm 0.62^{\mathrm{a}}$ & $30.78 \pm 1.16^{b}$ & $38.07 \pm 0.77^{a}$ & $35.30 \pm 1.47^{\mathrm{ab}}$ & $38.55 \pm 1.56^{\mathrm{a}}$ & $37.60 \pm 0.90^{a}$ & 5 & $7.41 * * *$ \\
\hline Percentage of below-ground carbon & $56.49 \pm 0.94^{b}$ & $70.83 \pm 3.14^{\mathrm{a}}$ & $58.90 \pm 1.05^{b}$ & $63.19 \pm 2.19^{\mathrm{ab}}$ & $58.53 \pm 2.58^{b}$ & $58.54 \pm 1.22^{b}$ & 5 & $6.56 * * *$ \\
\hline
\end{tabular}

Data are mean \pm SE. C, Control; inoculation with nematodes (Nem), AMF, inoculation with arbuscular mycorrhizal fungi and nematodes; FN, inoculation with arbuscular mycorrhizal fungi and nematodes; FN2, nematode inoculation 2 wk after AMF; FN5, nematode inoculation 5 wk after AMF. Different letters indicate significant differences between treatments according to one-way ANOVA and Tukey's HSD. ${ }^{* *}, P<0.001$. 
Table 3 Ammophila arenaria total biomass, root : total biomass ratio, length of longest leaf, number of tillers and number of leaves in experiment 2

\begin{tabular}{|c|c|c|c|c|c|c|c|c|}
\hline \multirow[b]{2}{*}{ Variable } & \multicolumn{8}{|l|}{ Treatment } \\
\hline & $\mathrm{C}$ & Nem & AMF & $\mathrm{FN}$ & Split & $F$ & $\mathrm{df}$ & $\chi^{2}$ \\
\hline Biomass (d. wt) (g) & $3.05 \pm 0.29$ & $2.66 \pm 0.33$ & $3.54 \pm 0.73$ & $2.52 \pm 0.56$ & $2.62 \pm 0.24$ & 1.06 nst & 4 & - \\
\hline Root : total & $0.37 \pm 0.03$ & $0.40 \pm 0.03$ & $0.36 \pm 0.04$ & $0.44 \pm 0.04$ & $0.48 \pm 0.05$ & 1.69 nst & 4 & - \\
\hline Longest leaf $(\mathrm{cm})$ & $67.66 \pm 2.64^{\mathrm{ab}}$ & $61.17 \pm 1.80^{\mathrm{a}}$ & $70.20 \pm 2.65^{b}$ & $54.80 \pm 1.80^{c}$ & $56.31 \pm 1.54^{\mathrm{ac}}$ & - & 4 & $19.82^{*} \neq$ \\
\hline Tillers & $6.11 \pm 1.14$ & $5.11 \pm 0.53$ & $5.75 \pm 1.37$ & $6.25 \pm 0.61$ & $5.25 \pm 0.70$ & - & 4 & 1.632 nsł \\
\hline Leaves & $14.00 \pm 2.12$ & $12.44 \pm 1.66$ & $17.25 \pm 4.38$ & $15.62 \pm 2.06$ & $12.00 \pm 1.42$ & - & 4 & 2.947 nsf \\
\hline
\end{tabular}

Data are mean \pm SE. C, Control; inoculation with nematodes (Nem), AMF, inoculation with arbuscular mycorrhizal fungi and nematodes; FN, inoculation with arbuscular mycorrhizal fungi and nematodes; Split, split inoculation of AMF and nematodes. Different letters indicate significant differences between treatments according to one-way ANOVA and Tukey's HSD ( $\dagger$ ) or nonparametric tests $(\ddagger) .{ }^{*}, P<0.05 ;{ }^{* *}, P<0.01$; ***,$P<0.005 ;$ ns, nonsignificant.

Table 4 Ammophila arenaria plant nitrogen and carbon content and percentage of nitrogen and carbon allocated below-ground in experiment 2

\begin{tabular}{lccccccc}
\hline & \multicolumn{2}{l}{ Treatment } & & & & \\
\cline { 2 - 7 } Variable & $\mathrm{C}$ & Nem & AMF & FN & Split & $\mathrm{df}$ & $F$ \\
\hline Plant nitrogen $(\% \mathrm{w}: \mathrm{w})$ & $0.97 \pm 0.01^{\mathrm{ab}}$ & $1.24 \pm 0.08^{\mathrm{a}}$ & $0.78 \pm 0.09^{\mathrm{ab}}$ & $0.87 \pm 0.06^{\mathrm{b}}$ & $0.93 \pm 0.10^{\mathrm{b}}$ & 4 & $5.46^{* * *}$ \\
Percentage of below-ground nitrogen & $31.18 \pm 4.47^{\mathrm{ab}}$ & $34.19 \pm 2.49^{\mathrm{a}}$ & $34.99 \pm 4.75^{\mathrm{ab}}$ & $30.16 \pm 1.76^{\mathrm{ab}}$ & $22.89 \pm 2.31^{\mathrm{b}}$ & 4 & $3.48^{*}$ \\
Plant carbon $(\% \mathrm{w}:$ w) & $36.28 \pm 1.77^{\mathrm{ab}}$ & $36.87 \pm 1.35^{\mathrm{a}}$ & $33.77 \pm 0.37^{\mathrm{ab}}$ & $31.24 \pm 1.01^{\mathrm{b}}$ & $37.95 \pm 1.68^{\mathrm{ab}}$ & 4 & $3.09^{*}$ \\
Percentage of below-ground carbon & $39.39 \pm 2.47^{\mathrm{ab}}$ & $39.46 \pm 2.36^{\mathrm{a}}$ & $39.37 \pm 4.48^{\mathrm{ab}}$ & $36.39 \pm 0.81^{\mathrm{ab}}$ & $28.07 \pm 2.43^{\mathrm{b}}$ & 4 & $4.01^{*}$ \\
\hline
\end{tabular}

Data are mean \pm SE. C, Control; inoculation with nematodes (Nem), AMF, inoculation with arbuscular mycorrhizal fungi and nematodes; FN, inoculation with arbuscular mycorrhizal fungi and nematodes; Split, split inoculation of AMF and nematodes. Different letters indicate significant differences between treatments according to one-way ANOVA and Tukey's HSD test. ${ }^{*}, P<0.05 ;{ }^{* * *}, P<0.005$; ns, nonsignificant.

percentage of root colonized by AMF were found between treatments. Root colonization by nematodes ranged between $15 \%$ and $26 \%$ and it was significantly reduced when nematodes and AMF were inoculated together (Fig. $4 \mathrm{~b}, F_{2,22}=6.44$, $P<0.01)$. The total number of nematodes and the number of nematodes per infected unit were also significantly lower $\left(F_{2,22}=3.94, P<0.05 ; F_{2,22}=6.05, P<0.005\right)$ when nematodes and AMF were inoculated together (Fig. 4c,d). The final number of nematodes per pot was 2152 in Nem and 795 in FN treatment. The inoculation of AMF and nematodes in different subsystems of the root did not reduce root colonization by nematodes, but a slight reduction in the total number of nematodes was observed.

No significant differences between the treatments were observed for plant biomass, ratio of biomass allocated below ground and for the number of tillers and leaves (Table 3 ). However, plants inoculated with AMF and nematodes in the same root (FN treatment) were significantly shorter than the control plants and plants inoculated with nematodes or AMF $\left(\chi^{2}=19.82, P<0.05\right)$.

In the split-root experiment, significant differences in nutrient content and allocation were found between the inoculation treatments (Table 4). Plants inoculated only with nematodes had a significantly higher $\mathrm{N}$ content than plants inoculated with both $\mathrm{AMF}$ and nematodes $\left(F_{4,24}=5.46\right.$; $P=0.003$ ) (Table 4). Significant differences in total C content were found between the plants inoculated only with nematodes and those inoculated with nematodes and AMF in the same root subsystem $\left(F_{4,24}=3.48 ; P=0.022\right)$. The highest proportion of $\mathrm{N}$ and $\mathrm{C}$ allocated below ground were observed in the plants inoculated only with nematodes and the lowest in the SPLIT treatment. Significant differences were found between these two values $\left(F_{4,24}=3.08, P=0.035\right.$ for belowground $\mathrm{N} ; F=4.01, P=0.013$ for below-ground $\mathrm{C}$ ).

\section{AMF diversity}

The diversity of the AMF associated with A. arenaria in both experiments was analysed because different AMF genera have morphological and functional differences that could be important for the interaction with the nematodes. Thirty-one different sequences were obtained from the analysis of DNA extracted from $A$. arenaria roots and are now deposited in GenBank (accession numbers DQ090845-DQ090875). All the sequences displayed a strong homology with sequences of Glomus spp. available in GenBank. The phylogenetic tree 
New

Phytologist

Fig. 5 Neighbour-joining tree inferred from partial SSU rDNA sequences obtained from Ammophila arenaria roots and other described and undescribed Glomus spp. Squares E1-E11, sequences obtained from experiment 1 (Trap cultures from Het Zwin, Belgium). Circles E12-E31, sequences obtained from experiment 2 (Trap cultures from Ynyslas, Wales, UK).

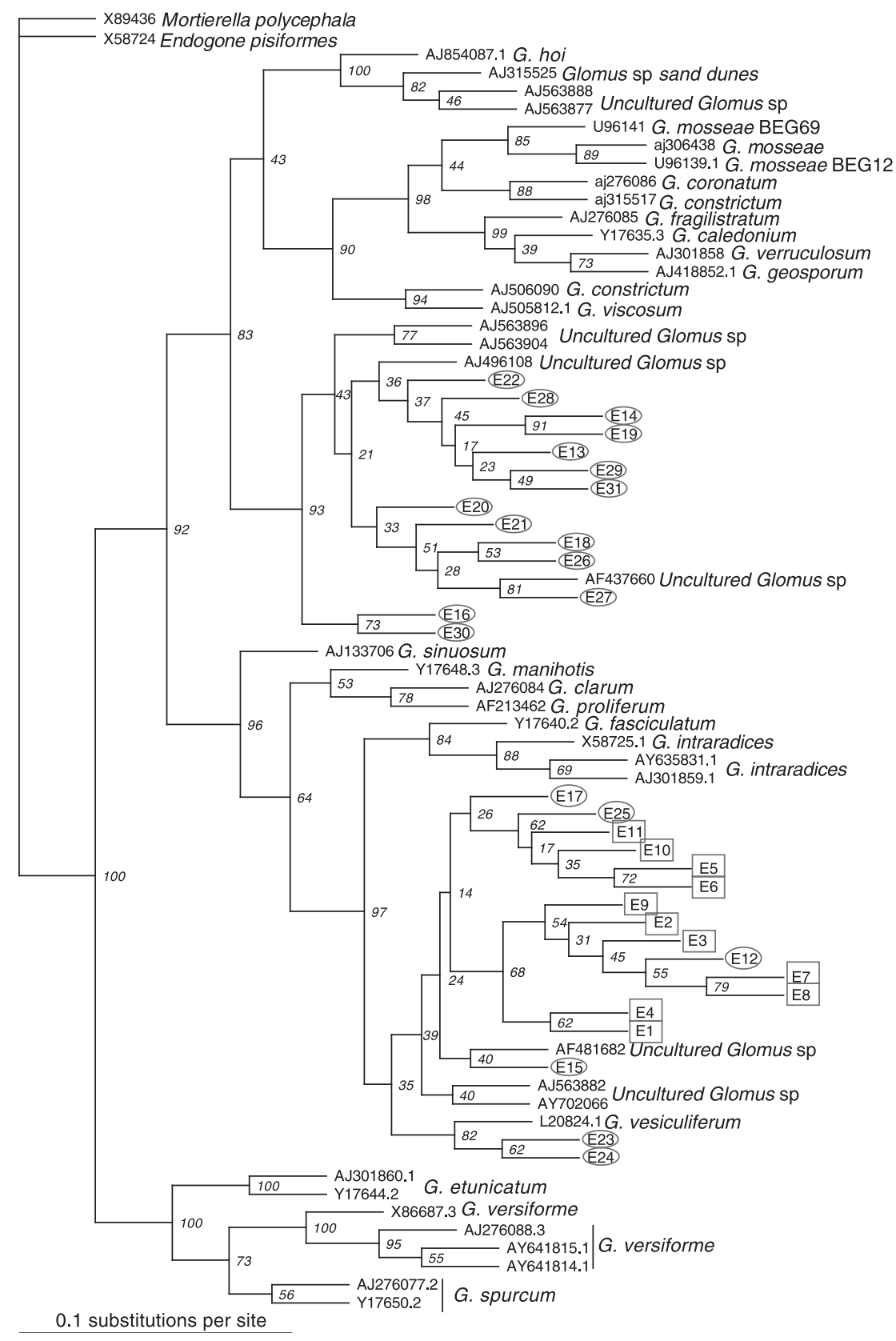

sequences obtained from studies in grasslands and northern forests (Vandenkoornhuyse et al., 2002; Öpik et al., 2003).

\section{Discussion}

Our results show that native AMF can protect $A$. arenaria through the suppression of $P$. penetrans colonization and reproduction. The process of $P$. penetrans suppression by AMF acts through locally operating mechanisms. In other studies on coastal dune systems, Greipsson \& El-Mayas (2002) found that a commercial AMF inoculum protected the dune grass Leymus arenarius against migratory endoparasitic nematodes. 
Little \& Maun (1996) showed that mycorrhizal protection of Ammophila brevigulata against Pratylenchus and Heterodera spp. was effective when sand burial occurred simultaneously. The majority of studies on the interaction between AMF and Pratylenchus spp. have been done with perennial crops and the results are inconsistent. Some showed increases in plant tolerance or resistance to Pratylenchus spp. as a consequence of plant inoculation with AMF, but others did not find any protective effect of AMF (Roncadori, 1997; Forge et al., 2001; Elsen et al., 2003).

The data presented here show, for the first time, that AMF can outcompete migratory endoparasitic nematodes when they occur together in the same root compartment; this contrasts with previous studies with migratory endoparasitic nematodes in which AMF appeared to enhance nematode multiplication (Borowicz, 2001). Conversely, root colonization by AMF was not affected by the migratory endoparasitic nematodes, so we did not detect mutual inhibition between AMF and nematodes as proposed previously (Francl, 1993). The detailed mechanisms of suppression of nematodes were not analysed; however, our results suggest that direct competition with AMF hyphae in the root or local changes in root chemistry or exudates may have been responsible for the inhibition of nematode reproduction (Graham, 2001).

Some authors have hypothesized that AMF protection is only effective if plants are colonized by the mycorrhizal fungi before the attack by pathogens and/or herbivores. This hypothesis is based on the improved nutritional and health status of mycorrhizal plants which allow them to support higher densities of root-feeding nematodes (Azcón-Aguilar \& Barea, 1996; Vaast et al., 1998). We did not find a higher concentration of $\mathrm{N}$ and $\mathrm{C}$ in the plants that were preinoculated with AMF $2 \mathrm{wk}$ and $5 \mathrm{wk}$ before nematode inoculation, but plant biomass was significantly higher in the FN5 treatment than when nematodes and AMF were inoculated simultaneously. However, this positive effect of AMF preinoculation might have occurred through nematode suppression and not through increased plant tolerance because the effect of preinoculation with AMF was a further reduction in nematode reproduction and infection.

Increases in plant growth through improved plant nutrient uptake are considered to be the main benefits that plants obtain from the symbiosis with AMF (Jeffries et al., 2003). A significant increase in plant growth was observed in the first experiment but not in the second one. This disparity might be caused by differences in the AMF species between both experiments, but also, and more likely, by the different age of the plants used in the two experiments, 2 wk vs. 8 wk, because younger $A$. arenaria plants display a greater response to AMF (Rodríguez-Echeverría et al., 2004). Thus, changes on plant biomass and nutrient content between treatments were not as severe in the split-root experiment as in the first experiment. The biomass allocated below ground was $20 \%$ in the sequential inoculation experiment and $40 \%$ in the split-root experiment.
The proportion of biomass allocated above and below ground by a plant species depends on environmental factors, plant age and growing time (Klepper, 1991). Because pot size was different in both experiments, the variation in the percentage of below-ground biomass could be explained not only by plant age but also by the greater sand volume that each plant had in the split-root experiment. It is noteworthy that in both experiments the proportion of biomass allocated below-ground increased with the inoculation of nematodes and/or AMF.

The presence of nematodes did not have a negative impact on plant growth. However, nematodes wiped out the beneficial effect of AMF and affected plant $\mathrm{N}$ and $\mathrm{C}$ content. These differences were again greater in the sequential inoculation experiment, probably because young plants are more sensitive to the attack by root-feeding herbivores (van der Putten et al., 1990). Plants in the sequential inoculation experiment also reallocated $\mathrm{N}$ and $\mathrm{C}$ above-ground when attacked by the nematodes, a common reaction in plants subjected to important root damage (Masters \& Brown, 1997). In the split-root experiment the highest $\mathrm{N}$ content was found in plants infected only by nematodes. Although these plants were probably more tolerant to herbivory than the 2-wk-old seedlings, this increase in $\mathrm{N}$ content can be considered an indicator of plant stress (Whittaker, 2003), as observed for A arenaria when growing in nonsterilized soil (van der Putten et al., 1988). Root colonization by AMF did not increase nutrient content in the plants of the split-root experiment, a fact that could be explained by the lower responsiveness of older seedlings combined with the lower values of root colonization by AMF.

The AMF communities associated with the roots of $A$. arenaria were very similar in both experiments, containing mainly Glomus sp. from the Glomus-group A (Schüßler et al., 2001). The genus Glomus comprises the majority of species within the phylum Glomeromycota. Glomus species are also more resistant to disturbances than other genera of AMF (Dodd et al., 2000). Therefore, the AMF communities detected on the roots probably represent the fraction of field inoculum that can survive and grow in our experimental conditions. As in other molecular studies of AMF colonizing plant roots, our sequences did not correspond to previously described AMF species suggesting a higher natural AMF diversity than acknowledged from culture collections. Our understanding of the importance of AMF diversity for the symbiosis is still limited, however, the interactions of plants with complex natural AMF communities are probably richer than with commercial AMF inocula. Studies addressing ecological issues should not underestimate the importance of the natural high diversity of AMF

The ability of AMF to control $P$. penetrans in the rhizosphere of $A$. arenaria could be crucial under natural field conditions. A study by van der Stoel et al. (2002) showed that root-feeding nematodes, including Pratylenchus spp., accumulate in $4-5 \mathrm{wk}$ after the growth of new roots in the new 
fresh sand layer. They found that the density of nematodes (and other adverse soil organisms), after a month of the sand deposition, could significantly reduce growth of test plants in glasshouse trials. However, they also observed that in the field, mature $A$. arenaria can overcome that negative effect of nematodes in the foredunes. Arbuscular mycorrhizal fungi were excluded from their glasshouse trials, but our results demonstrate that the interaction between $A$. arenaria and rootfeeding nematodes cannot be fully understood without AMF.

The diversity of organisms involved in below-ground interactions makes it difficult to single-out the direct implications and effects of different groups; however, our results show that AMF can control root herbivores associated with the grass $A$. arenaria. This mechanism can be added to the bottom-up and interspecific competition processes that have been previously reported as regulatory of nematode populations in coastal dunes (Brinkman et al., 2004). The role of nematode antagonists, the effect of AMF in other nematode genera and the consequences of this interaction for nematode competition needs further consideration to completely understand nematode control in natural systems.

\section{Acknowledgements}

We thank Dr Chris Walker for the identification of AMF spores and Kris Struyf for allowing collection of samples at Het Zwin Nature Reserve. We are also grateful to Dr Reinier Mann, Dr Gera Hol and two anonymous referees for their comments on the manuscript. This work was funded by the EU project EcoTrain (HPRN-CT-2002-00210).

\section{References}

Altschul SF, Madden TL, Schaffer AA, Zhang J, Zhang Z, Miller W, Lipman DJ. 1997. Gapped BLAST and PSI-BLAST: a new generation of protein database search programs. Nucleic Acids Research 25: 3389-3402.

Azcón-Aguilar C, Barea JM. 1996. Arbuscular mycorrhizas and biological control of soil-borne plant pathogens - an overview of the mechanisms involved. Mycorrhiza 6: 457-464.

Back MA, Haydock PP, Jenkinson P. 2002. Disease complexes involving plant parasitic nematodes and soilborne pathogens. Plant Pathology 51: 683-697.

Baker TJ, Gowen SR. 1996. Staining nematodes and arbuscular mycorrhizae in the same root sample. Fundamental and Applied Nematology 19: 607-608.

Bever JD. 2003. Soil community feedback and the coexistence of competitors: conceptual framework and empirical tests. New Phytologist 157: 465-473.

Borowicz VA. 2001. Do arbuscular mycorrhizal fungi alter plant-pathogen relations? Ecology 82: 3057-3068.

Brinkman EP, Duyts H, van der Putten WH. 2005. Consequences of variation in species diversity in a community of root-feeding herbivores for nematode dynamics and host plant biomass. Oikos 110: 417-427.

Brinkman EP, van Veen JA, van der Putten WH. 2004. Plant recruitment of endoparasitic nematodes may influence, but not regulate ectoparasitic nematodes. Applied Soil Ecology 27: 65-75.
De Deyn GB, Raaijmakers CE, van der Putten WH. 2004. Plant community development is affected by nutrients and soil biota. Journal of Ecology 92: 824-834.

Dodd JC, Boddington CL, Rodriguez A, Gonzalez-Chavez C. 2000. Mycelium of Arbuscular Mycorrhizal fungi (AMF) from different genera: form, function and detection. Plant and Soil 226: 131-151.

Elsen A, Beeterens R, Swennen R, De Waele D. 2003. Effects of an arbuscular mycorrhizal fungus and two plant-parasitic nematodes on Musa genotypes differing in root morphology. Biology and Fertility of Soils 38: 367-376.

Felsenstein J. 1993. PHYLIP, 3.5 edn. Seattle, WA, USA: Department of Genetics, University of Washington (distributed by the author).

Forge T, Muehlchen A, Hackenberg C, Neilsen G, Vrain T. 2001. Effects of preplant inoculation of apple (Malus domestica Borkh.) with arbuscular mycorrhizal fungi on population growth of the root-lesion nematode, Pratylenchus penetrans. Plant and Soil 236: 185-196.

Francl LJ. 1993. Interactions of nematodes with mycorrhizae and mycorrhizal fungi. In: Khan MW, ed. Nematode interactions. London, UK: Chapman \& Hall, 203-216.

Gange AC, Brown VK. 2002. Actions and interactions of soil invertebrates and arbuscular mycorrhizal fungi in affecting the structure of plant communities. In: van der Heijden MGA, Sanders IR, eds. Mycorrhizal ecology. Berlin, Germany: Springer-Verlag, 321-344.

Giovannetti M, Mosse B. 1980. An evaluation of techniques for measuring vesicular arbuscular mycorrhizal infection in roots. New Phytologist 84: 489-500.

Graham JH. 2001. What do root pathogens see in mycorrhizas? New Phytologist 149: 357-359.

Greipsson S, El-Mayas H. 2002. Synergistic effect of soil pathogenic fungi and nematodes reducing bioprotection of Arbuscular mycorrhizal fungi on the grass Leymus arenarius. Biocontrol 47: 715-727.

Hall TA. 1999. BIOEDIT: a user-friendly biological sequence alignment editor and analysis program for Windows 95/98/NT. Nucleic Acids Symposium Serial 41: 95-98.

Helgason T, Daniell TJ, Husband R, Fitter AH, Young JPW. 1998. Ploughing up the woodwide web? Nature 394: 431.

Hendrickx GA. 1995. Automatic apparatus for extracting free-living nematodes stages from soil. Nematologica 41: 30.

Hol WHG, Cook R. 2005. An overview of arbuschular mycorrhizal fungi-nematode interactions. Basic and Applied Ecology. doi:10.1016/j.baae.2005.04.001

Jeffries P, Gianinazzi S, Perotto S, Turnau K, Barea JM. 2003. The contribution of arbuscular mycorrhizal fungi in sustainable maintenance of plant health and soil fertility. Biology and Fertility of Soils 37: 1-16.

Karssen G, van Aelst A, Waeyenberge L, Moens M. 2001. Observations on Pratylenchus penetrans Cobb, 1917 parasitizing the coastal dune grass Ammophila arenaria (L.) Link in the Netherlands. Journal of Nematode Morphology and Systematics 1: 1-9.

Kimura M. 1980. A simple model for estimating evolutionary rates of base substitutions through comparative studies of nucleotide sequences. Journal of Molecular Evolution 16: 111-120.

Klepper B. 1991. Root-shoot relationships. In: Waisel Y, Eshel A, Kafkafi U, eds. Plant roots: the hidden half. New York, USA: Marcel Dekker, 265-286.

Klironomos JN. 2002. Feedback with soil biota contributes to plant rarity and invasiveness in communities. Nature 417: 67-70.

Klironomos JN. 2003. Variation in plant response to native and exotic arbuscular mycorrhizal fungi. Ecology 84: 2292-2301.

Little LR, Maun MA. 1996. The 'Ammophila problem' revisited: a role for mycorrhizal fungi. Journal of Ecology 84: 1-7.

Marshall JK. 1965. Corynephorus canescens (L.) P. Beauv. as a model for the Ammophila problem. Journal of Ecology 53: 447-463.

Masters GJ, Brown VK. 1997. Host-plant mediated interactions between spatially separated herbivores: effects on community structure. In: Gange AC, 
Brown VK, eds. Multitrophic interactions in terrestrial ecosystems. The 36th Symposium of the British Ecological Society. Oxford, UK: Blackwell Science, 217-138.

Olsson PA, Wilhelmsson P. 2000. The growth of external AM fungal mycelium in sand dunes and in experimental systems. Plant and Soil 226 161-169.

Öpik M, Moora M, Liira J, Köljalg U, Zobel M, Sen R. 2003. Divergent arbuscular mycorrhizal fungal communities colonize roots of Pulsatilla spp. in boreal Scots pine forest and grassland soils. New Phytologist 160: 581-593.

Page RDM. 2001. TREEVIEW 1.6.6. Glasgow, UK: Division of Environmental and Evolutionary Biology, Institute of Biomedical and Life Sciences, University of Glasgow (distributed by the author).

Pinochet J, Calvet C, Camprubi A, Fernandez C. 1996. Interactions between migratory endoparasitic nematodes and arbuscular mycorrhizal fungi in perennial crops: a review. Plant and Soil 185: 183-190.

Reinhart KO, Packer A, van der Putten WH, Clay K. 2003. Plant-soil biota interactions and spatial distribution of black cherry in its native and invasive ranges. Ecology Letters 6: 1046-1050.

Rodríguez-Echeverría S, Crisóstomo J, Freitas H. 2004. Arbuscular mycorrhizal fungi associated with Ammophila arenaria L. in European coastal sand dunes. In: Arianotsou M, Papanastasis D, eds. Proceedings of the 10th International Conference on Mediterranean Climate Ecosystems, Rhodes, Greece. Rotterdam, the Netherlands: Millpress, 1-7.

Roncadori RW. 1997. Interactions between arbuscular mycorrhizas and plant parasitic nematodes in agro-ecosystems. In: Gange AC, Brown VK, eds. Multitrophic interactions in terrestrial systems. The 36th Symposium of the British Ecological Society. Oxford, UK: Blackwell Science, 101-114.

de Rooij-van der Goes PCEM. 1995. The role of plant-parasitic nematodes and soil-borne fungi in the decline of Ammophila arenaria (L.) Link. New Phytologist 129: 661-669.

de Rooij-van der Goes P, Peters BAM, van der Putten WH. 1998. Vertical migration of nematodes and soil-borne fungi to developing roots of Ammophila arenaria (L.) Link after sand accretion. Applied Soil Ecology 10: $1-10$.

Schüßler A, Schwarzott D, Walker C. 2001. A new fungal phylum, the Glomeromycota: phylogeny and evolution. Mycological Research 105: 1413-1421.

Seliskar DM, Huettel RN. 1993. Nematode involvement in the die-out of Ammophila breviligulata Poaceae on the mid-Atlantic coastal dunes of the United States. Journal of Coastal Research 9: 97-103.

Simon L, Lalonde M, Bruns TD. 1992. Specific amplification of $18 \mathrm{~S}$ fungal ribosomal genes from vesicular-arbuscular mycorrhizal fungal communities. Applied and Environmental Microbiology 58: 291-295. van Tuinen D, Jacquot E, Zhao B, Gollote A, Gianinazzi-Pearson V. 1998.
Characterization of root colonization profiles by a microcosm community of arbuscular mycorrhizal fungi using $25 \mathrm{~S}$ rDNA-targeted nested PCR. Molecular Ecology 7: 879-887.

Vaast P, Caswell-Chen EP, Zasoski RJ. 1998. Influences of a root-lesion nematode, Pratylenchus coffeae, and two arbuscular mycorrhizal fungi, Acaulospora mellea and Glomus clarum on coffee (Coffea arabica L.). Biology and Fertility of Soils 26: 130-135.

van der Putten WH. 2003. Plant defense below ground and spatio-temporal processes in natural vegetation. Ecology 84: 2269-2280.

van der Putten WH, van Dijk C, Troelstra SR. 1988. Biotic soil factors affecting the growth and development of Ammophila arenaria. Oecologia 76: 313-320.

van der Putten WH, Maas PWT, van Gulik WJM, Brinkman H. 1990. Characterization of soil organisms involved in the degeneration of Ammophila arenaria. Soil Biology and Biochemistry 22: 845-852.

van der Putten WH, van Dijk C, Peters BAM. 1993. Plant-specific soil-borne diseases contribute to succession in foredune vegetation. Nature 362: 53-56.

van der Stoel CD, van der Putten WH, Duyts H. 2002. Development of a negative plant-soil feedback in the expansion zone of the clonal grass Ammophila arenaria following root formation and nematode colonization. Journal of Ecology 90: 978-988.

Vandenkoornhuyse P, Husband R, Daniell TJ, Watson IJ, Duck JM, Fitter AH, Young JPW. 2002. Arbuscular mycorrhizal community composition associated with two plant species in a grassland ecosystem. Molecular Ecology 11: 1555-1564.

Vierheilig H, Coughlan AP, Wyss U, Piché Y. 1998. Ink and vinegar, a simple staining technique for arbuscular-mycorrhizal fungi. Applied and Environmental Microbiology 64: 5004-5007.

Wardle DA. 2002. Belowground consequences of aboveground food web interactions. In: Levine SAH, ed. Communities and ecosystems. Princeton, NJ, USA: Princeton University Press, 105-137.

White TJ, Bruns T, Lee S, Taylor J. 1990. Amplification and direct sequencing of fungal ribosomal RNA genes for phylogenetics. In: Innis MA, Gelfand DH, Sminski JJ, White TJ, eds. PCR protocols: a guide to methods and applications. San Diego, CA, USA: Academic Press, 315-322.

Whittaker JB. 2003. Root-animal interactions. In: de Kroon H, Visser EJW, eds. Root ecology. Berlin, Germany: Springer-Verlag, 363-385.

Wirsel SGR. 2004. Homogenous stands of a wetland grass harbour diverse consortia of arbuscular mycorrhizal fungi. FEMS Microbiology Ecology 48: $129-138$.

Zoon FC, Troelstra SR, Maas PWT. 1993. Ecology of the plant-feeding nematode fauna associated with sea buckthorn (Hippophae rhamnoides 1-ssp rhamnoides) in different stages of dune succession. Fundamental and Applied Nematology 16: 247-258. 